Research Article

\title{
Investigation on the Removal of Carbon Dioxide Exhausted from Industrial Units in a Lab-Scale Fluidized Bed Reactor
}

\author{
Puriya Mohamad Gholy Nejad, Mohammad Sadegh Hatamipour*
}

Chemical Engineering Department, Faculty of Engineering, University of Isfahan, Isfahan, Iran.

Received: $5^{\text {th }}$ June 2020; Revised: 9th July 2020; Accepted: $9^{\text {th }}$ July 2020; Available online: 30th July 2020; Published regularly: August 2020

\begin{abstract}
In this study, $\mathrm{CO}_{2}$ removal efficiency from flue gas was investigated in a fluidized bed reactor under semi-dry conditions. A lab-scale fluidized bed reactor, filled with inert glass beads, was used to investigate the effect of operating parameters on the $\mathrm{CO}_{2}$ removal efficiency using calcium hydroxide slurry as the absorbent. The Taguchi design method was used to design the experiments. The maximum inlet concentration of $\mathrm{CO}_{2}$ was $3 \mathrm{vol} \%$. The most important factors were the reaction surface area, inlet gas velocity, inlet $\mathrm{CO}_{2}$ concentration, absorbent solution flow rate, inlet gas temperature and calcium hydroxide slurry concentration. The experimental results indicated that the $\mathrm{CO}_{2}$ removal efficiency increased when increasing the effective surface area of the reaction. Moreover, the removal efficiency increased by decreasing the input gas flow rate and inlet $\mathrm{CO}_{2}$ concentration. By performing experiments under optimum conditions, the maximum obtained $\mathrm{CO}_{2}$ removal efficiency was $79 \%$. Copyright $\mathbb{C} 2020$ BCREC Group. All rights reserved
\end{abstract}

Keywords: Absorption; Carbon capture; $\mathrm{Ca}(\mathrm{OH})_{2}$; Fluidized bed; Taguchi design; $\mathrm{CO}_{2}$ removal

How to Cite: Nejad, P.M.G., Hatamipour, M.S. (2020). Investigation on the Removal of Carbon Dioxide Exhausted from Industrial Units in a Lab-Scale Fluidized Bed Reactor. Bulletin of Chemical Reaction Engineering \& Catalysis, 15(2), 579-590 (doi:10.9767/bcrec.15.2.7882.579-590)

Permalink/DOI: https://doi.org/10.9767/bcrec.15.2.7882.579-590

\section{Introduction}

In recent years, the global fossil fuel consumption has significantly increased, leading to the increased carbon dioxide $\left(\mathrm{CO}_{2}\right)$ concentration in the atmosphere. $\mathrm{CO}_{2}$ accounts for about 80 percent of greenhouse gas emissions. The global warming effect of greenhouse gases is a critical issue which has received great attention $[1,2]$. The issue has brought the world to the brink of a significant human and environmental catastrophe. Scientists believe that $\mathrm{CO}_{2}$ emission due to the consumption of fossil and miner-

* Corresponding Author.

E-mail: hatami@eng.ui.ac.ir (M.S. Hatamipour);

Tel: +98 313 7937047; fax: +98 3137937031 al fuels is the primary source of such problems in industrialized and semi-industrialized countries. For instance, in Iran alone fuel combustion emitted about 552 million tons of $\mathrm{CO}_{2}$ per year [3]. If this trend persists, it will reach about 90 billion tons of $\mathrm{CO}_{2}$ per year in the world by 2050. However, the earth cannot absorb more than 12 billion tons of $\mathrm{CO}_{2}$ [4]. Oil, coal and natural gas have remained significant sources of energy in the world. The industrial sector accounted for nearly one-third of the global primary energy consumption and about a quarter of global energy and $\mathrm{CO}_{2}$ emissions in 2005. Industrial furnaces and cement kilns emit $\mathrm{CO}_{2}$ with a much higher concentration than coal-fired power plants [5,6]. Thus, $\mathrm{CO}_{2}$ emis- 
sions have increased considerably over the past decade. Developing new technologies and improving existing technologies can reduce $\mathrm{CO}_{2}$ emissions. Several processes, such as postcombustion, pre-combustion and oxyfuel technology, have been proposed for the $\mathrm{CO}_{2}$ removal from flue gases. Among these processes, the post-combustion process can be used for new power plants. Application of the $\mathrm{CO}_{2}$ removal process to conventional power plants is considered as a post-combustion process in which lowpressure exhaust gases pass through a separation process eliminating the $\mathrm{CO}_{2}$. Due to the mass transfer restrictions against absorbing acid gases in the traditional gas-liquid contractors such as packed-bed towers and spray towers, new contact types are developing [7].

The calcium loop is a post-combustion $\mathrm{CO}_{2}$ adsorption process that includes two fluidized bed reactors with a continuous loop of lime $(\mathrm{CaO})$. In this system, the carbonate reaches a high temperature (about $600-700{ }^{\circ} \mathrm{C}$ ) and adsorbs a high $\mathrm{CO}_{2}$ concentration using the $\mathrm{CaO}$. The flue gas exits with a low $\mathrm{CO}_{2}$ concentration. As presented in Table 1, in the previous studies [8-17], the $\mathrm{CO}_{2}$ removal efficiency did not reach $100 \%$, and about $1-3 \mathrm{vol} \%$ of $\mathrm{CO}_{2}$ remained in the flue gas. The main purpose of this study is to increase the $\mathrm{CO}_{2}$ removal efficiency by reducing its content in the exit gas close to zero, without spending extra energy. A review of the existing literature demonstrates that no study has been conducted in this field. The $\mathrm{CO}_{2}$ removal processes from the flue gas are generally divided into three categories of wet, dry and semi-dry processes. Wet or dry processes can be easily distinguished by knowing whether the removal agent contains a liquid solution. In a semi-dry process, $\mathrm{CO}_{2}$ is re- moved by contact with a suitable absorbent, such as $\mathrm{CaO}$ slurry. In this method, the slurry is pumped into rotary atomizers or fluid nozzles that produce droplets by spraying. According to the purpose of the gas and liquid contact in the wet process or the flue gas cleaners based on the semi-dry process, three types of devices can be used which are reactive spray dryer, spouted bed reactor and fluidized bed reactor $[7,18,19]$. Among the mentioned devices, the fluidized bed reactor has a lower pressure drop and higher removal efficiency. For existing combustion systems, the only available technology for $\mathrm{CO}_{2}$ separation is very lowtemperature absorption processes [20]. Absorbent-based processes were using chemical solvents commonly referred to in literature include: ammonia, ethanolamine, sodium hydroxide solution and calcium hydroxide [21]. Han et al. [22] investigated the $\mathrm{CO}_{2}$ absorption performance for an inlet gas with $30 \mathrm{vol} \% \mathrm{CO}_{2}$ using an aqueous calcium hydroxide solution. They proved that among six absorbents, the aqueous solution of saturated calcium hydroxide had the highest absorption rate and ratio. The absorption capacity of saturated calcium hydroxide is 3.2 grams of $\mathrm{CO}_{2}$ per gram of calcium hydroxide, which is three times higher than that of $1 \%$ calcium hydroxide solution.

Thus, hydrated lime is a sound absorbent for $\mathrm{CO}_{2}$ removal in the chemical industries. It is an economical sorbent due to its advantages such as relatively high conversion, availability and efficiency [23]. Consequently, the objective of the present work is to achieve removal of lower $\mathrm{CO}_{2}$ concentrations in the flue gases of industrial plants. In addition to the effective removal of pollutant gases, fluidized bed reactors have advantages such as high reliability,

Table 1. Review of carbonate looping experiments at lab or pilot scale.

\begin{tabular}{lcc}
\hline Description (scale and location) & $\begin{array}{c}\text { Inlet } \\
\% \mathrm{CO}_{2}\end{array}$ & $\begin{array}{c}\text { Outlet } \\
\% \mathrm{CO}_{2}\end{array}$ \\
\hline A 10 kW pilot-scale at the University of Stuttgart Figure 5 [17] & $13.0-15.4$ & $0.55-1.7$ \\
Lab and pilot-scale at the University of Stuttgart Figure 3 [18] & 15.7 & $0.5-1.4$ \\
A 1 MW pilot-scale at IFK, University of Stuttgart Figure 14 [19] & 15.4 & $0.4-2.15$ \\
A 1 MW pilot-scale at the Technical University Darmstadt Figure 7 [20] & 15 & $1.15-3.2$ \\
A 10 kW pilot-scale at the Technical University Darmstadt Figure 3 [21] & 13.5 & $2-3.3$ \\
A 1.7 MW pilot-scale dual fluidized bed study IFK Figure 2 [22] & 13 & $1.9-3.2$ \\
A 0.1 MW pilot-scale Figures 2, 3 and 5 [23] & 8.59 & $0.8-3.6$ \\
A pilot-scale dual fluidized bed study Figure 4 [24] & 16 & $0.4-3$ \\
A laboratory-scale dual fluidized bed at INCAR-CSIC (Spain) and IFK & 11.4 & $1.7-2.5$ \\
(Germany) Figure 4 [25] & & \\
A pilot-scale dual fluidized bed study Figure 1 [26] & 8 & $0.4-2.3$ \\
\hline
\end{tabular}


low initial and operational costs, low capacity, low energy consumption and high absorption capacity due to extended gas and liquid contact area.

\section{Materials and Methods}

\subsection{Theoretical Analysis}

In the experimented fluidized bed, which was a cylindrical bed with a gas distributor, a variety of particle sizes were used for the reaction. The $\mathrm{Ca}(\mathrm{OH})_{2}$ slurry was continuously fed to the fluidized bed. When the slurry droplets came into contact with the particles, a thin film of the slurry covered the particle surface. The reaction occurred between the $\mathrm{CO}_{2}$ from the gas phase and the absorbent in the slurry phase on the surface of the particles. The water simultaneously evaporated from the surface forming a dry layer on the particle surface. Due to the movement of particles, the dried and reacted absorbents in powder form were separated from the particles' surface. Finally, the powder was dried by the flue gas and removed from the bed. In the present study, the particles not only played the role of support for the liquid film but also provided a high surface area for the reactants [24]. In this process, heat and mass transfer as well as chemical reactions occurred in the reactor, simultaneously.

This process can be explained by two stages (1) the formation of calcium carbonate and (2) the evaporation of the water droplets. The first stage can be described as a succession of the following equations [7]:

(a). The mass transfer of $\mathrm{CO}_{2}$ from the gas flow to the surface of droplets, absorption at the solid surface, $\mathrm{CO}_{2}$ dissolution at the interface and $\mathrm{CO}_{2}$ solution formation:

$$
\mathrm{CO}_{2(g)} \rightarrow \mathrm{CO}_{2(a q)}
$$

(b). Combining $\mathrm{CO}_{2}$ with water in the slurry:

$$
\mathrm{CO}_{2(a q)}+\mathrm{H}_{2} \mathrm{O}_{(l)} \rightarrow \mathrm{H}_{2} \mathrm{CO}_{3(l)}
$$

(c). Dissociation of liquid carbonate into carbonate and protons:

$$
\mathrm{H}_{2} \mathrm{CO}_{3}(l)=\mathrm{HCO}_{3}^{-}+\mathrm{H}^{+}=\mathrm{CO}_{3}^{2-}+2 \mathrm{H}^{+}
$$

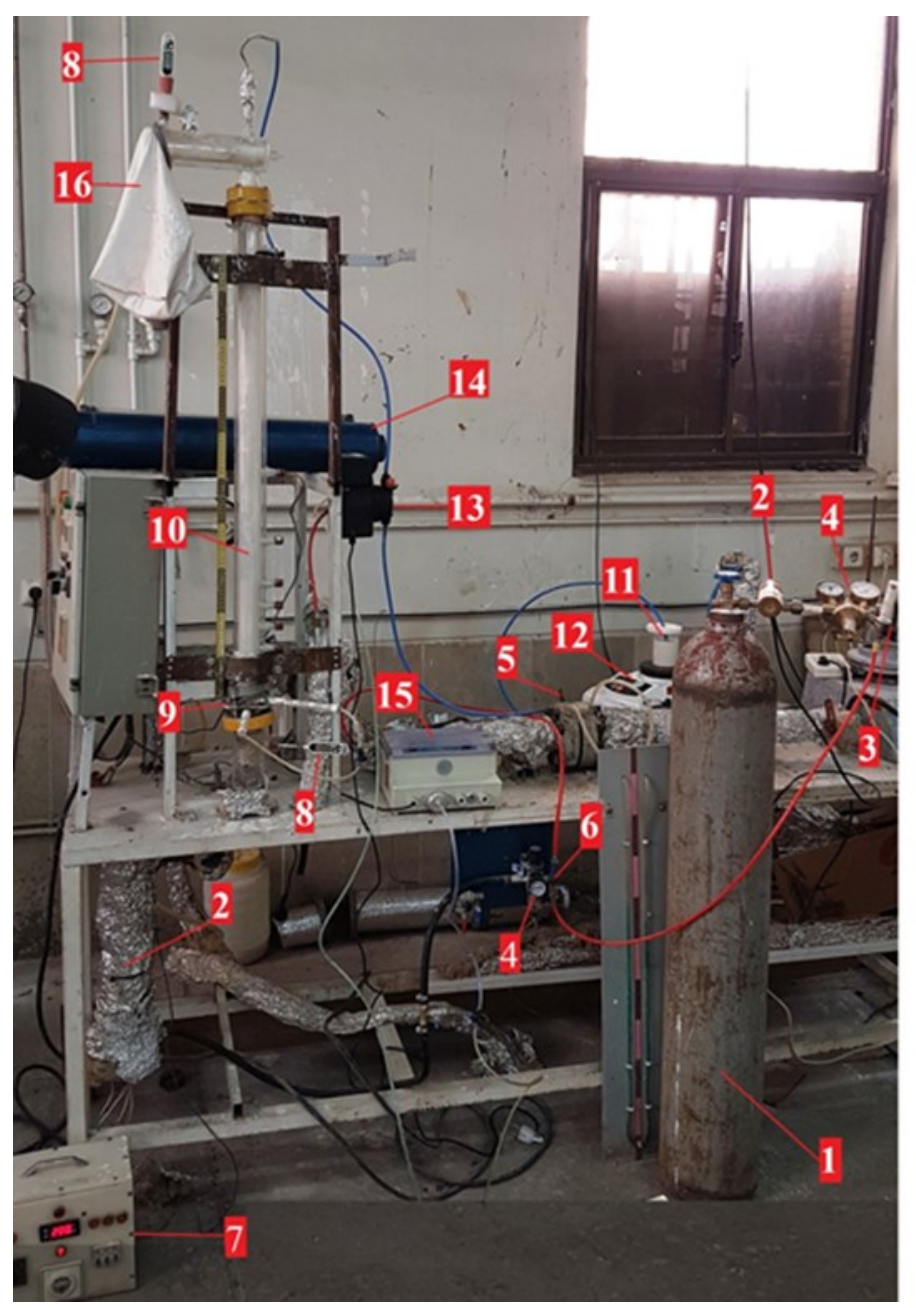

1. $\mathrm{CO}_{2}$ capsule

2. Heater

3. Rotameter

4. Pressure gauge

5. Orifice flow meter

6. Static mixer

7. Temperature controller

8. Temperature gauge

9. Mesh plate

10. Fluidized bed reactor

11. Slurry tank

12. Magnetic stirrer

13. Prostatic pump

14. Sample cooler

15. $\mathrm{CO}_{2}$ analyzer

16. Filter bag

Figure 1. Photographic view of the experimental fluidized bed system. 
(d). Decomposition of hydrated calcite absorbent in the slurry droplets:

$$
\mathrm{Ca}(\mathrm{OH})_{2(s)}=\mathrm{Ca}(\mathrm{OH})_{2(a q)}=\mathrm{Ca}_{(a q)}^{2+}+2 \mathrm{OH}_{(a q)}^{-}
$$

(e). Deposition of calcium carbonate:

$$
\mathrm{CO}_{3}^{2-}(a q)+\mathrm{Ca}_{(a q)}^{2+}=\mathrm{CaCO}_{3(s)}
$$

The overall reaction is the summation of Equations (1-5) which can be written as:

$$
\mathrm{Ca}(\mathrm{OH})_{2(s)}+\mathrm{CO}_{2(g)}=\mathrm{CaCO}_{3(s)}+\mathrm{H}_{2} \mathrm{O}_{(l)}
$$

The second stage for the water evaporation can be expressed as:

$$
\mathrm{H}_{2} \mathrm{O}_{(l)}=\mathrm{H}_{2} \mathrm{O}_{(v)}
$$

\subsection{Materials}

Large calcium hydroxide pellets (Merck, Germany) were purchased from chemical agents in Isfahan, Iran. $\mathrm{CaO}$ agglomerates were grounded and sieved into fine particles to facilitate its hydration. In the reactor, the spherical glass particles had a diameter of 0.4$0.7 \mathrm{~mm}$ and a density of $2400 \mathrm{~kg} / \mathrm{m}^{3}$.

\subsection{Experimental Procedure}

The reactor used in this study was a labscale fluidized bed. It was made of a Pyrex ${ }^{\circledR}$ column with a height of $100 \mathrm{~cm}$ and a nominal diameter of $50 \mathrm{~mm}$. A photographic view of the device is shown in Figure 1. The $\mathrm{Ca}(\mathrm{OH})_{2}$ slur-

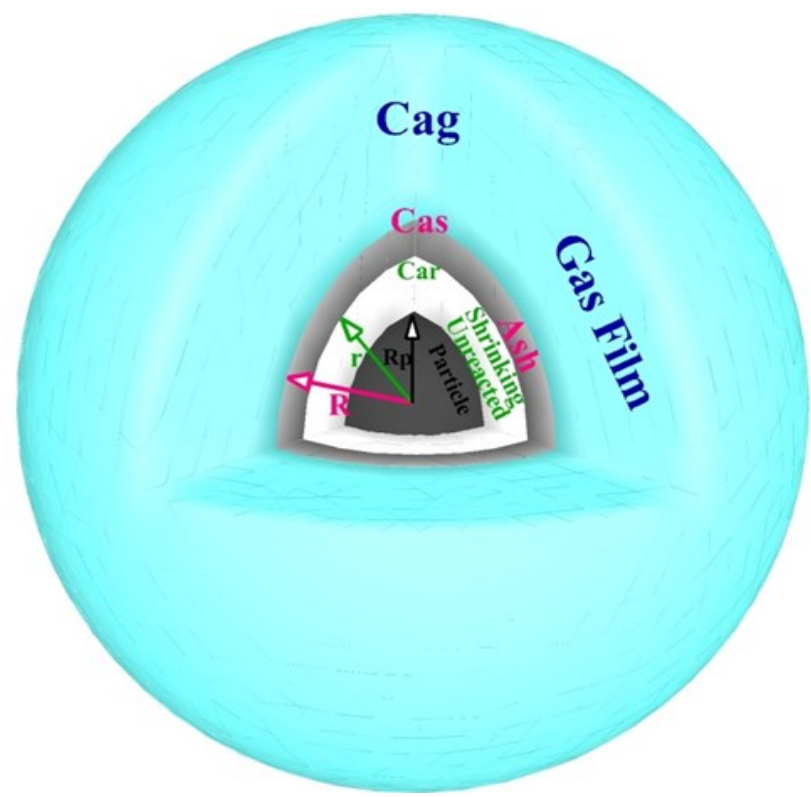

Figure 2. Schematic representation of the shrinking core model (SCM) for describing the reaction. ry was prepared by hydrating the $\mathrm{CaO}$ particles in water. This slurry was stored in a closed stirred tank. Glass particles were loaded to the desired height in the bed. Air was supplied by a central compressor after passing through an oil filter. The $\mathrm{CO}_{2}$ flow was regulated by a flowmeter. $\mathrm{A} \mathrm{CO}_{2}$ analyzer (Guardian Plus-D600) was used to measure the $\mathrm{CO}_{2}$ concentration at the inlet and outlet of the gas stream. The flue gas (the mixture of air and $\mathrm{CO}_{2}$ ) was heated by an electric heater and fed from the bottom of the reactor after passing through the inlet distributor. The gas temperature was measured by a thermocouple at the reactor inlet and controlled by a controller. The fresh slurry was injected into the reactor by an injection pump, and the bed particles were impregnated with the slurry. As a result of $\mathrm{CO}_{2}$ absorption by the slurry, the gas temperature was dropped to the adiabatic saturation temperature. This phenomenon occurred due to the heat transfer from the gas to the slurry and water evaporation from the slurry. The decarbonated gas was passed through some filters to remove fine droplets and solid particles. Thereafter, the gas was sent to the stack and eventually discharged into the atmosphere.

\subsection{Reaction Analysis by Shrinking Core Model}

The $\mathrm{Ca}(\mathrm{OH})_{2}$ slurry was continuously fed to the fluidized bed. When spraying the $\mathrm{Ca}(\mathrm{OH})_{2}$ slurry into the bed, a thin film was formed on the particle surface, where a reaction occurred between $\mathrm{CO}_{2}$ and $\mathrm{Ca}(\mathrm{OH})_{2}$ according to Equation 6 . The liquid water on the surface of the particle evaporated from it simultaneously (see Equation 7), forming a hard solid coating around each particle.

Beruto \& Botter [25] showed that absorption of water vapor from the sorbent particles creates a liquid layer interface where $\mathrm{Ca}(\mathrm{OH})_{2}$, $\mathrm{CO}_{2}$ and $\mathrm{CaCO}_{3}$ are dissolved. At low $\mathrm{CO}_{2}$ concentrations, both its solubility and mass transfer rate affect the reaction rate. Thus, it seems that more comprehensive research is needed to study the reaction between $\mathrm{CO}_{2}$ and $\mathrm{Ca}(\mathrm{OH})_{2}$ in fluidized bed reactors at semi-dry and low $\mathrm{CO}_{2}$ concentrations. Since the water evaporation coincided with chemical reaction, this reaction can be treated similar to a fluid-solid reaction. Thus, the shrinking core model (SCM) can be applied for describing this reaction (see Figure 2). According to this model, the reaction takes place first at the outer surface of the layer. Then, the reaction domain moves toward the inner layer. Once the reaction is completed, the converted material remains as an inert solid 
which is called ash. For this case, the rate steps for the reaction of $\mathrm{CO}_{2}(\mathrm{~A})$ with $\mathrm{Ca}(\mathrm{OH})_{2}$ slurry (B) can be written as:

Step 1. Diffusion of A through the gas film encircling the particle to its surface:

$$
\dot{n}_{A}=\frac{4 \pi R^{2} K_{g}\left(C_{A g}-C_{A s}\right)}{4 / 3 \pi R^{3}\left[1-\left(\frac{R_{p}}{R}\right)^{3}\right]}
$$

Step 2. Diffusion of A through the ash layer to the unreacted core surface:

$$
\dot{n}_{A}=\frac{4 \pi D_{e}\left(C_{A s}-C_{A r}\right)}{\frac{4}{3} \pi R^{3}\left[1-\left(\frac{R_{p}}{R}\right)^{3}\right]\left(\frac{1}{r}-\frac{1}{R}\right)}
$$

Step 3. Chemical reaction of A with the slurry of B:

$$
\dot{n}_{A}=\frac{4 \pi r^{2} K C_{B} C_{A r}}{\frac{4}{3} \pi R^{3}\left[1-\left(\frac{R_{p}}{R}\right)^{3}\right]}
$$

Considering a quasi-steady-state condition, the right-hand sides of Equations 8-10 are equal. By eliminating the interfacial concentrations $C_{A g}$ and $C_{A r}$, the following equation is obtained:

$$
\dot{n}_{A}=\frac{C_{A g}}{\frac{4}{3} \pi R^{3}\left[1-\left(\frac{R_{p}}{R}\right)^{3}\right]\left[\frac{1}{4 \pi R^{2} k_{g}}+\frac{\left(\frac{1}{r}-\frac{1}{R}\right)}{4 \pi D_{e}}+\frac{1}{4 \pi r^{2} K C_{B}}\right]}
$$

$\dot{n}_{A}$ is not constant, but in this case, due to the low residence time of slurry and $\mathrm{CO}_{2}$ in the fluidized bed reactor, high surface area between the liquid and gas, and using mean values for the variable parameters, $\dot{n}_{A}$ was considered to be constant. Thus, by substitution of the unreacted core radius, and $K C_{B}$ in Equation 11 the following equation is obtained:

$$
r=\frac{R}{2}
$$

$$
\begin{aligned}
& \text { where } K^{\prime}=K C_{B}=\text { cte } \\
& \dot{n}_{A}=\frac{C_{A g}}{\frac{R^{3}}{3}\left[1-\left(\frac{R_{p}}{R}\right)^{3}\right]\left[\frac{1}{R^{2} k_{g}}+\frac{1}{R D_{e}}+\frac{4}{R^{2} K^{\prime}}\right]}
\end{aligned}
$$

Equation 12 could be represented as Equation 13:

$$
\dot{n}_{A}=K_{a p p} C_{A g}
$$

where

$$
K_{a p p}=\frac{1}{\frac{R}{3}\left[1-\left(\frac{R_{p}}{R}\right)^{3}\right]\left[\frac{1}{k_{g}}+\frac{R}{D_{e}}+\frac{4}{K^{\prime}}\right]}
$$

In Equation 14, it is not possible to directly measure the parameters $\left(R, k_{g}, D_{e}\right.$ and $\left.K^{\prime}\right)$. Therefore, in this study, measurable parameters in experiments that have a very favorable effect on $R, k g, D e$ and $K^{\prime}$, along with the relationship that $K_{a p p}$ has with these parameters, are obtained. Here, $R$ depends on the reaction surface area and inlet gas velocity; $K^{\prime}$ on the inlet temperature, the $\mathrm{Ca}(\mathrm{OH})_{2}$ slurry concentration and flow rate; and $k_{g}$ mostly on the $\mathrm{CO}_{2}$ concentration, inlet gas temperature and velocity. In addition, the mean of $\mathrm{CO}_{2}$ concentration and Taguchi methodology were used for experimental $K_{a p p}$ calculation.

\subsection{Design of Experiments}

The Taguchi method for design of experiments is a statistical method that reduces the number of tests. Such an approach can examine the effect of different parameters on the results. As mentioned in the previous sections, the effects of 6 parameters on the absorption of $\mathrm{CO}_{2}$ by an absorbent in a fluidized bed reactor were investigated. Each parameter was investigated at three levels. The parameters and their levels are shown in Table 2. The response was the removal efficiency expressed as:

$$
\eta=\frac{C_{\text {in }}-C_{\text {out }}}{C_{\text {in }}} \times 100
$$

Table 2. Parameters and their levels in the experimental design.

\begin{tabular}{lccc}
\hline Level Parameter & Level 1 & Level 2 & Level 3 \\
\hline Reaction surface area $\left(\mathrm{m}^{2}\right)(\mathrm{A})$ & 0.359 & 0.609 & 1.059 \\
Inlet gas velocity $(\mathrm{m} / \mathrm{s})(\mathrm{B})$ & 0.9 & 1.1 & 1.3 \\
$\mathrm{Ca}(\mathrm{OH})_{2}$ slurry concentration $(\mathrm{g} / \mathrm{mL} / \mathrm{h})(\mathrm{C})$ & 0.32 & 0.42 & 0.52 \\
Inlet $\mathrm{CO}_{2}$ concentration $(\mathrm{vol} \%)(\mathrm{D})$ & 1 & 2 & 3 \\
Inlet slurry flow rate $(\mathrm{mL} / \mathrm{min})(\mathrm{E})$ & 10 & 15 & 20 \\
Inlet gas temperature $\left({ }^{\circ} \mathrm{C}\right)(\mathrm{F})$ & 150 & 200 & 250 \\
\hline
\end{tabular}


To design the tests using the Taguchi method, the software Minitab ${ }^{\circledR}$ Release 16.2.4.4 was used which returned a standard L27 array. In order to reduce errors during data collection, each analysis was carried out twice. The experimental operating conditions and obtained removal efficiency values are shown in Table 3. To analyze the results, the signal-to-noise ratio $(\mathrm{S} / \mathrm{N})$ was used as a corrected response in the Taguchi method, which shows the rate of variation in the response due to the difference in the factors controlled by their error ratio. Therefore, the following equation was used to maximize the removal efficiency [26]:

$$
\frac{S}{N}=-10 \times \log \left[\frac{\sum_{1}^{n}\left(\frac{1}{y_{n}^{2}}\right)}{n}\right]
$$

Analysis of variance (ANOVA), as shown in Table 4, is a reliable tool in the Taguchi method. In the ANOVA table, P-values lower than 0.05 indicate that the changes occur with $95 \%$ confidence. Therefore, it is assumed that a $\mathrm{P}$ value above 0.05 indicates little impact on the response. The F-value in the ANOVA table is a reliable criterion to distinguish the important

Table 3. Taguchi L27 orthogonal array and the responses.

\begin{tabular}{cccccccccc}
\hline Trial & A & B & C & D & F & E & Response 1 & Response 2 & $K_{a p p}$ \\
\hline 1 & 1 & 1 & 1 & 1 & 1 & 1 & 51.5 & 53.3 & 0.016120 \\
2 & 1 & 1 & 1 & 1 & 2 & 2 & 60.0 & 65.0 & 0.021298 \\
3 & 1 & 1 & 1 & 1 & 3 & 3 & 56.6 & 55.0 & 0.017729 \\
4 & 1 & 2 & 2 & 2 & 1 & 1 & 49.5 & 45.0 & 0.013889 \\
5 & 1 & 2 & 2 & 2 & 2 & 2 & 57.5 & 54.3 & 0.017778 \\
6 & 1 & 2 & 2 & 2 & 3 & 3 & 56.6 & 45.0 & 0.015402 \\
7 & 1 & 3 & 3 & 3 & 1 & 1 & 32.7 & 30.5 & 0.008247 \\
8 & 1 & 3 & 3 & 3 & 2 & 2 & 43.3 & 39.0 & 0.011513 \\
9 & 1 & 3 & 3 & 3 & 3 & 3 & 36.7 & 34.8 & 0.009606 \\
10 & 2 & 1 & 2 & 3 & 1 & 2 & 50.0 & 61.0 & 0.017582 \\
11 & 2 & 1 & 2 & 3 & 2 & 3 & 57.5 & 55.0 & 0.017951 \\
12 & 2 & 1 & 2 & 3 & 3 & 1 & 53.3 & 55.0 & 0.016933 \\
13 & 2 & 2 & 3 & 1 & 1 & 2 & 55.0 & 56.6 & 0.017729 \\
14 & 2 & 2 & 3 & 1 & 2 & 3 & 57.5 & 55.0 & 0.017951 \\
15 & 2 & 2 & 3 & 1 & 3 & 1 & 56.7 & 52.5 & 0.017147 \\
16 & 2 & 3 & 1 & 2 & 1 & 2 & 52.5 & 58.3 & 0.017533 \\
17 & 2 & 3 & 1 & 2 & 2 & 3 & 58.3 & 55.0 & 0.018151 \\
18 & 2 & 3 & 1 & 2 & 3 & 1 & 57.5 & 51.5 & 0.017099 \\
19 & 3 & 1 & 3 & 2 & 1 & 3 & 60.0 & 65.0 & 0.021298 \\
20 & 3 & 1 & 3 & 2 & 2 & 1 & 65.0 & 70.0 & 0.024406 \\
21 & 3 & 1 & 3 & 2 & 3 & 2 & 72.5 & 67.5 & 0.026144 \\
22 & 3 & 2 & 1 & 3 & 1 & 3 & 58.3 & 61.7 & 0.019897 \\
23 & 3 & 2 & 1 & 3 & 2 & 1 & 68.3 & 63.3 & 0.023299 \\
24 & 3 & 2 & 1 & 3 & 3 & 2 & 70.0 & 65.0 & 0.024406 \\
25 & 3 & 3 & 2 & 1 & 1 & 3 & 62.5 & 57.5 & 0.019897 \\
26 & 3 & 3 & 2 & 1 & 2 & 1 & 65.0 & 62.5 & 0.022035 \\
27 & 3 & 3 & 2 & 1 & 3 & 2 & 67.5 & 65.0 & 0.023586 \\
\hline
\end{tabular}

Table 4. Analysis of variance (ANOVA) for $\mathrm{S} / \mathrm{N}$ ratios.

\begin{tabular}{lccccc}
\hline Source & Degree of freedom & Sum of squares & Main squares & F-value & P-Value \\
\hline Surface area & 2 & 34.7903 & 17.3951 & 688.98 & 0 \\
Velocity & 2 & 10.1732 & 5.0866 & 201.47 & 0 \\
$\mathrm{Ca}(\mathrm{OH})_{2}$ & 2 & 6.9877 & 3.4939 & 138.38 & 0 \\
$\% \mathrm{CO}_{2}$ & 2 & 8.9682 & 4.4841 & 177.60 & 0 \\
Heater T & 2 & 3.4107 & 1.7054 & 67.54 & 0 \\
Flow slurry & 2 & 2.7722 & 1.3861 & 54.90 & 0 \\
\hline Residual & 14 & 0.3535 & 0.0252 & & \\
Total & 26 & 67.4557 & & & \\
\hline
\end{tabular}


factors from the less essential ones. A higher Fvalue indicates that the factor has a more significant impact on the result [27]. It should be noted that the interpretation of the ANOVA table is valid only within the range of levels investigated for each factor. That is why the choice of scale in every test of the design method is critical. The test conditions are briefly summarized in Table 4. In this table, each experiment was repeated twice.

\section{Results and Discussion}

The ANOVA analysis for $\mathrm{CO}_{2}$ removal efficiency is shown in Table 4. As can be seen, none of the $\mathrm{P}$-values is greater than 0.05 . Therefore, all factors have a significant impact on the response. This table shows that the effective surface area of the reaction is the most effective factor.

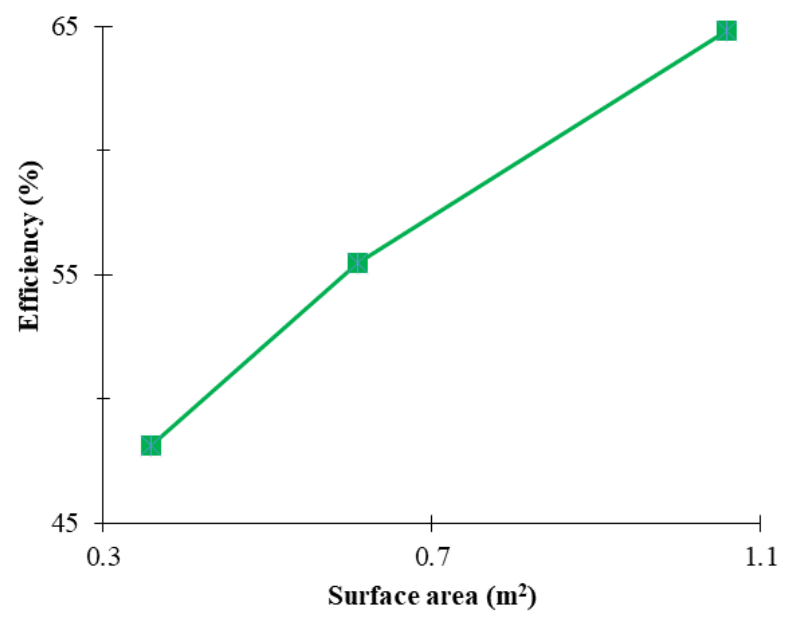

Figure 3. The effect of surface area $\left(\mathrm{m}^{2}\right)$ on the removal efficiency.

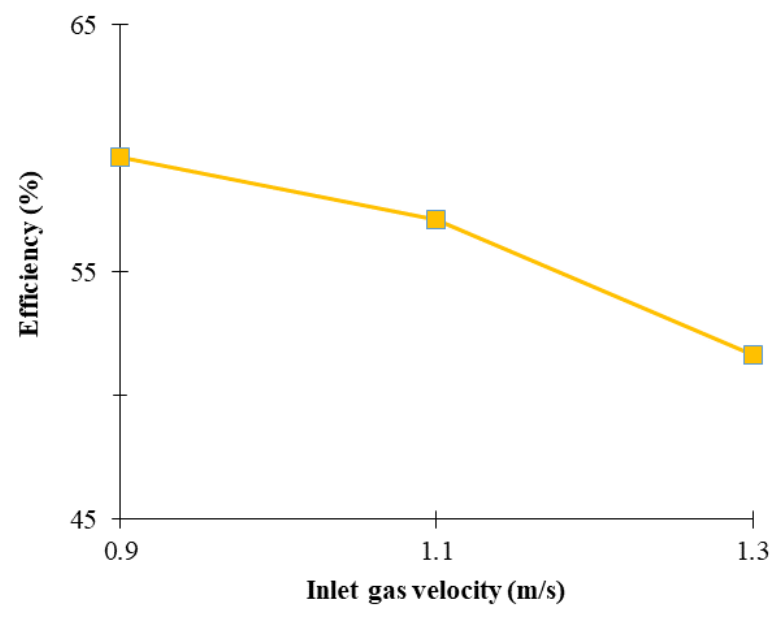

Figure 4. The effect of inlet gas velocity $(\mathrm{m} / \mathrm{s})$ on the removal efficiency.
Moreover, based on the F-value, the factors can be ranked in the order of importance as (1) reaction surface area, (2) inlet gas velocity, (3) inlet $\mathrm{CO}_{2}$ concentration, (4) solution flow rate, (5) inlet gas temperature and (6) calcium hydroxide slurry concentration. Figures 3 to 8 show the effect of removal efficiency when the factors vary at different levels. Each point in these figures shows the average value of the two repetitive tests at the corresponding level.

\subsection{Reaction Surface Area}

According to Figure 3, the highest level for the surface area (i.e. $1.059 \mathrm{~m}^{2}$ ) is the optimal value. The effective reaction surface area is directly related to the particle size and bed height in the fluidized bed reactor. The particles with small size possess a high special surface area for the reaction, which enhances the mass transfer and $\mathrm{CO}_{2}$ absorption by the slurry. In addition, by increasing the bed height in the fluidized bed reactor, the number of particles within the reactor increases. This not only provides more contact area for the reactants but also increases the contact time between the $\mathrm{CO}_{2}$ and $\mathrm{Ca}(\mathrm{OH})_{2}$ in the reactor.

\subsection{Inlet Gas Velocity}

Figure 4 indicates that the lowest level of inlet gas velocity is more desirable for the inlet gas velocity. In this process, both the particle velocity and gas residence time are affected by the inlet gas velocity. A decrease in the gas velocity increases the residence time of the absorbent particles in the bed. Similar to fixed beds this increases the contact time between the reactants. Therefore, $\mathrm{CO}_{2}$ removal efficiency increases when decreasing the inlet gas velocity.

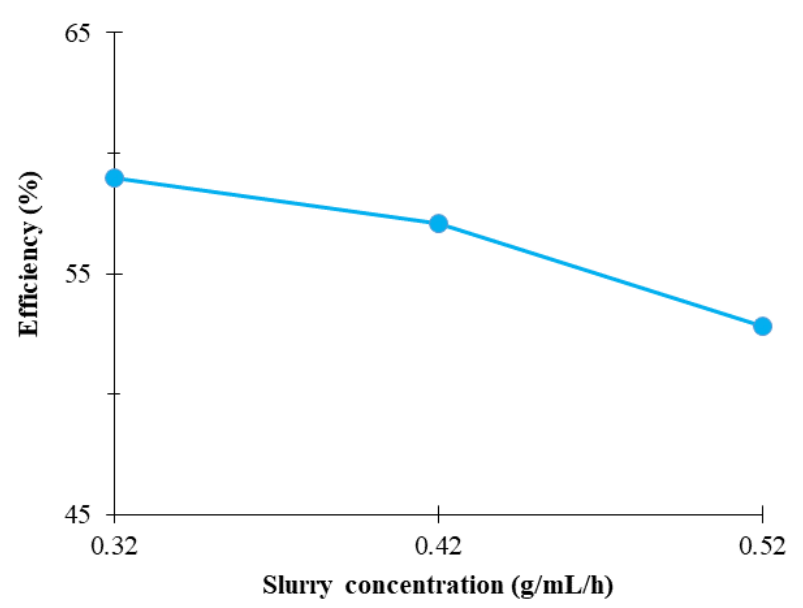

Figure 5. The effect of calcium hydroxide slurry concentration $(\mathrm{g} / \mathrm{mL} / \mathrm{h})$ on the removal efficiency. 
The reason for selecting $0.9 \mathrm{~m} / \mathrm{s}$ as the lowest level of inlet gas velocity was due to some technical limitations that were present. Some of these limitations are the bonding of the particles together and occurrence of agglomeration the fluidized bed that clogs the reactor wall when injecting $\mathrm{Ca}(\mathrm{OH})_{2}$ slurry into the reactor.

\subsection{Calcium Hydroxide Slurry Concentration}

Figure 5 shows that the highest absorption efficiency is achieved when the calcium hydroxide slurry concentration is at its lowest level. Generally, increasing the calcium hydroxide concentration in the inlet solution increases the density and viscosity of the slurry. This reduces the diffusion rate of $\mathrm{CO}_{2}$ into the liquid layer formed on the particles inside the reactor. On the other hand, increasing the calcium hydroxide concentration in the inlet slurry increases the amount of reactant in the reactor, which theoretically can increase the rate of reaction. The interaction of these two determines the effect of the calcium hydroxide slurry concentration on the $\mathrm{CO}_{2}$ removal efficiency. Since the solubility of calcium hydroxide in water is very low, the calcium hydroxide slurry contains undissolved particles together with the calcium and hydroxide ions in droplets and on the particles' surface. This result also was observed in previous works, such as Shih et al. [19]. They stated that the controlling step in kinetics of the reaction of $\mathrm{Ca}(\mathrm{OH})_{2}$ with $\mathrm{CO}_{2}$ is the dissolution of $\mathrm{Ca}(\mathrm{OH})_{2}$ in water. Therefore, inside the reactor, calcium hydroxide particles are insoluble in water droplets and on the surface of the bed particles. Moreover, the water evaporates faster when there is exposed to high temperature flue gas in the fluidized bed reactor. Thus,

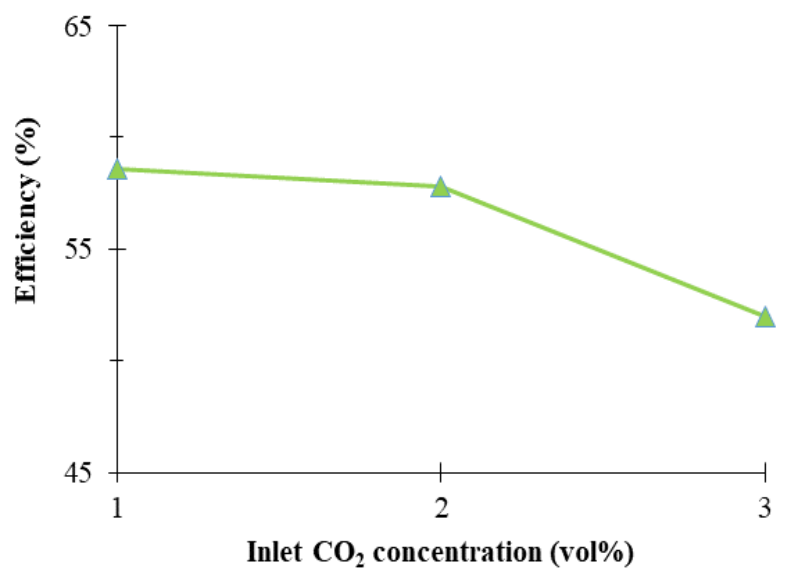

Figure 6. The effect of inlet $\mathrm{CO}_{2}$ concentration (vol\%) on the removal efficiency. the slurry droplets are dried faster and calcium oxide particles leave the reactor without participating in the reaction. Consequently, this effect is more prevalent in these experiments and higher absorption efficiency is obtained at lower concentrations of calcium hydroxide slurry.

\subsection{Inlet $\mathrm{CO}_{2}$ Concentration}

For the inlet $\mathrm{CO}_{2}$ concentration, Figure 6 shows that the lowest level is more suitable for achieving the highest absorption efficiency. According to Equation 11, three resistances affect the overall reaction rate: (1) diffusion resistance through the gas film to the ash layer on the unreacted core surface, (2) diffusion resistance through the ash layer to the unreacted core surface and (3) the chemical reaction resistance in the shrinking unreacted core. Beruto \& Botter [25] showed that at high $\mathrm{CO}_{2}$ concentrations, its solubility at the shrinking unreacted core interface is not the controlling stage of the reaction. It means that the $\mathrm{CO}_{2}$ concentration does not affect the reaction rate. In contrast, at lower $\mathrm{CO}_{2}$ concentrations, both $\mathrm{CO}_{2}$ solubility and mass transfer rate affect the overall reaction rate. The reason is that the mass transfer in the gas phase and $\mathrm{CO}_{2}$ solubility in the liquid interface is low. For low $\mathrm{CO}_{2}$ concentrations when the calcium hydroxide slurry concentration is constant, the ratio of lime to $\mathrm{CO}_{2}$ is high; in other words, more calcium hydroxide is available for the reaction. This result was also observed in previous works, such as in references $[7,18]$. Thus, the chemical reaction resistance does not affect the overall reaction rate. Consequently, the removal efficiency increases when the inlet $\mathrm{CO}_{2}$ con-

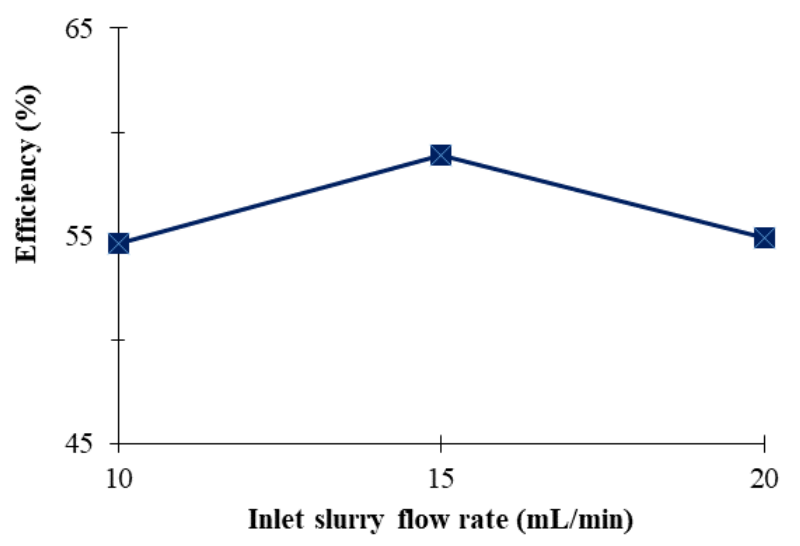

Figure 7. The effect of inlet flow rate of $\mathrm{Ca}(\mathrm{OH})_{2}$ slurry $(\mathrm{mL} / \mathrm{min})$ on the removal efficiency. 
centration decreases because the speed of the reaction increases by increasing the ratio of $\mathrm{Ca}(\mathrm{OH})_{2}$ to $\mathrm{CO}_{2}$.

\subsection{Inlet Slurry Flow Rate}

Figure 7 shows that the best $\mathrm{CO}_{2}$ absorption efficiency is achieved when the inlet flow rate of $\mathrm{Ca}(\mathrm{OH})_{2}$ slurry is at its mid-level. For a low inlet slurry flow rate, less water enters the reactor. Overall, the presence of water promotes the ionic reaction between $\mathrm{CO}_{2}$ and calcium hydroxide. Thus, the absorbent substance dries faster, forming a solid hard coating around each particle in the fluidized bed reactor, dropping the $\mathrm{CO}_{2}$ removal efficiency accordingly. Increasing the inlet slurry flow rate reduces the

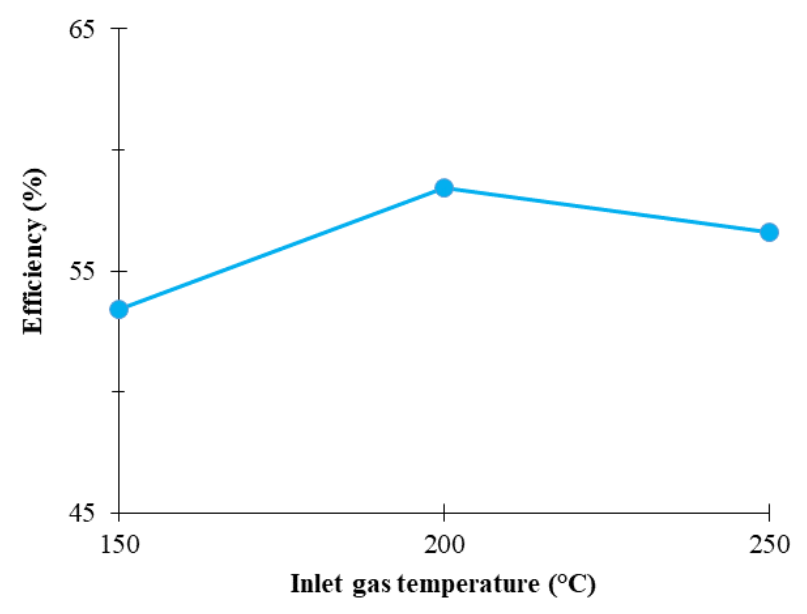

Figure 8. The effect of inlet gas temperature $\left({ }^{\circ} \mathrm{C}\right)$ on the removal efficiency. evaporation of the liquid phase within the reactor and increases the possibility of the ionic reaction between $\mathrm{CO}_{2}$ and calcium hydroxide. As the inlet slurry flow rate increases, the particles are bonded together, and agglomeration occurs. In addition, the formation of a liquid film on the reactor wall was observed in the experiments. This may be related to the limitations of the setup. This results in a decrease in the surface area between the absorbent and gas, leading to less absorption.

\subsection{Inlet Gas Temperature}

The inlet gas temperature affects the overall reaction rate between $\mathrm{CO}_{2}$ and calcium hydroxide [23]. According to Figure 8, the temperature level of $200{ }^{\circ} \mathrm{C}$ is desirable for achieving the highest absorption efficiency. At higher temperatures, the water in the absorbent evaporates faster. Thus the ionic reaction rate between $\mathrm{CO}_{2}$ and calcium hydroxide decreases, forming a hard solid coating around calcium hydroxide faster, and reducing the $\mathrm{CO}_{2}$ removal efficiency accordingly.

The residual plots are used to determine the model precision. A presumption plot is constructed with residual values. When this presumption is acquiescent, then the residual plot almost inclines to a straight line. The residual plot is shown in Figure 9. Based on the results, the optimum conditions for the mentioned setup are $1.059 \mathrm{~m}^{2}$ for the reaction surface area, $0.9 \mathrm{~m} / \mathrm{s}$ for the inlet gas velocity, $0.32 \mathrm{~g} / \mathrm{mL} / \mathrm{h}$ for the absorbent concentration, 1 vol\% for the

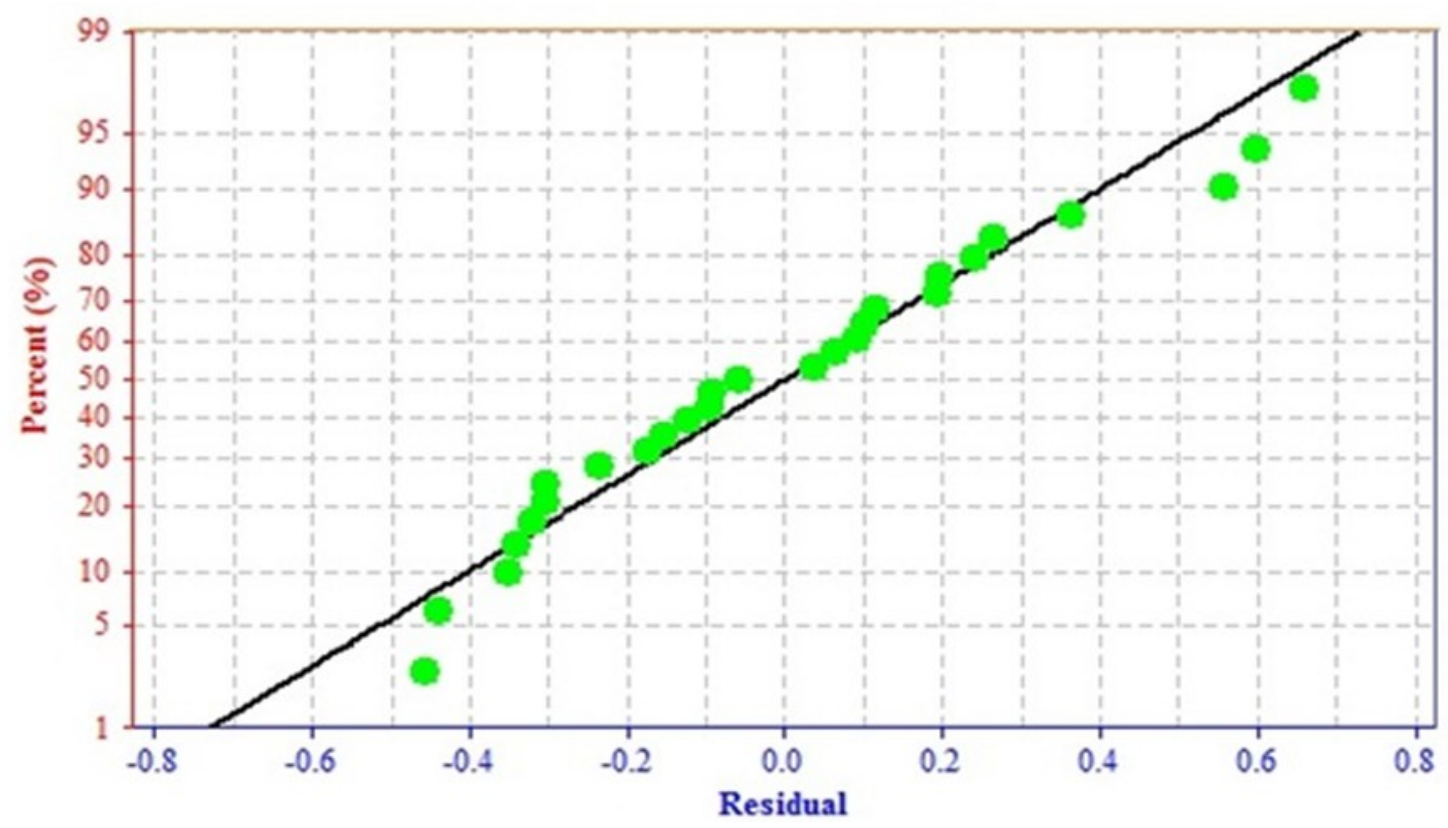

Figure 9. The residual plot difference between predicted and experimental data. 
inlet $\mathrm{CO}_{2}$ concentration, $15 \mathrm{~mL} / \mathrm{min}$ for the slurry flow rate and $200{ }^{\circ} \mathrm{C}$ for the inlet gas temperature. By performing experiments under the optimum conditions, the $\mathrm{CO}_{2}$ absorption efficiency is concluded from Figure 10 is $79 \%$, being higher than the values reported in Table 3. In this way, the optimality of the condition was verified.

3.7 Effect of Approach Temperature on the Efficiency

In the semi-dry process, the difference between the gas temperature in the reactor and the saturation temperature is a critical parameter affecting the efficiency. This approach temperature is a criterion that shows the relative humidity of the inlet gas. The effect of this parameter on the absorption efficiency is displayed in Table 5 and Figure 10. Under the ideal adiabatic condition, the lowest approach temperature is close to the saturation temperature. At this temperature, the gas reaches a relative humidity of $100 \%$. The gas temperature in the reactor and its relative humidity affect the drying rate of the absorbent. Therefore,

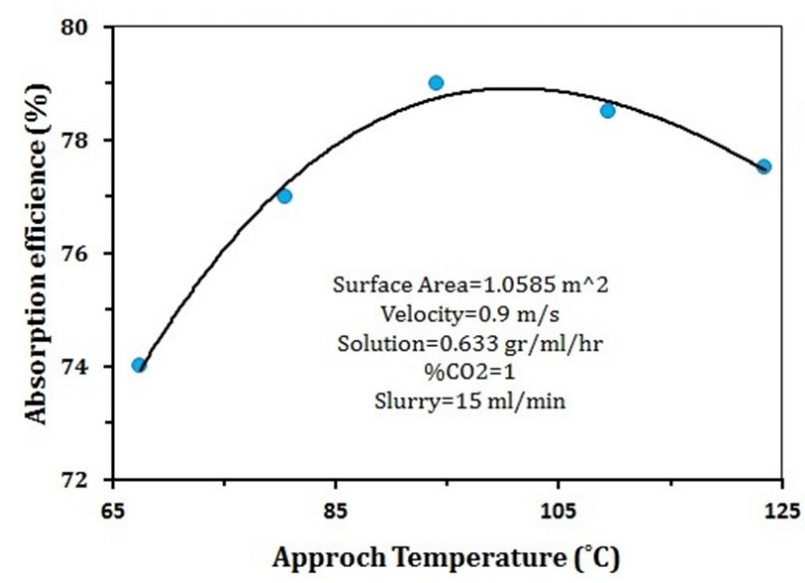

Figure 10. The effect of approach temperature on the absorption efficiency. the absorption rate and the amount of water contained in the slurry can be expressed by the approach temperature. When this temperature is small, the gas relative humidity is high, and the water evaporation rate is low $[7,28,29]$. Consequently, a higher amount of $\mathrm{CO}_{2}$ mixes with water in the slurry, and since the carbonation reaction of $\mathrm{Ca}(\mathrm{OH})_{2}$ is an ionic reaction, it is effectual for improving the reaction rate.

Thus, the removal efficiency increases when decreasing the approach temperature. On the other hand, if the gas inlet temperature is too low, the reaction between $\mathrm{Ca}(\mathrm{OH})_{2}$ and $\mathrm{CO}_{2}$ becomes slow. In contrast, if the temperature is too high, the water in the slurry absorbent evaporates faster. Consequently, this decreases the possibility of the ionic reaction between $\mathrm{CO}_{2}$ and calcium hydroxide. Therefore, the optimum value of the temperature should be selected by considering all conditions of the process. In these experiments, the highest efficiency was obtained at the optimum temperature of $200^{\circ} \mathrm{C}$.

\section{Conclusion}

In this study, the removal of $\mathrm{CO}_{2}$ in a labscale fluidized bed reactor was investigated under low-pressure conditions. The influence of different design parameters of inlet slurry flow rate, inlet $\mathrm{CO}_{2}$ concentration, absorbent slurry concentration, inlet gas velocity, surface area of the particles in the bed, and inlet gas temperature was investigated. Based on the design of experiments, the mentioned design parameters have a significant effect on the $\mathrm{CO}_{2}$ removal where increasing the bed surface area (i.e. increasing the bed static height and decreasing particle diameter size in the bed) enhances the $\mathrm{CO}_{2}$ absorption efficiency. On the other hand, increasing the gas flow rate, $\mathrm{CO}_{2}$ concentration and inlet gas velocity decreases the removal efficiency.

Table 5. The test conditions to investigate the effect of approach temperature on the absorption efficiency.

\begin{tabular}{ccccccccc}
\hline $\begin{array}{c}\text { Level } \\
\text { of A }\end{array}$ & $\begin{array}{c}\text { Level } \\
\text { of B }\end{array}$ & $\begin{array}{c}\text { Level } \\
\text { of C }\end{array}$ & $\begin{array}{c}\text { Level } \\
\text { of D }\end{array}$ & $\begin{array}{c}\text { Level } \\
\text { of F }\end{array}$ & $\begin{array}{c}\text { Level } \\
\text { of } \mathrm{E}\end{array}$ & $\begin{array}{c}\text { Inlet saturated } \\
\text { temperature } \\
\left({ }^{\circ} \mathrm{C}\right)\end{array}$ & $\begin{array}{c}\text { Outlet } \\
\text { temperature } \\
\left({ }^{\circ} \mathrm{C}\right)\end{array}$ & $\begin{array}{c}\text { Approach } \\
\text { temperature } \\
\left({ }^{\circ} \mathrm{C}\right)\end{array}$ \\
\hline 3 & 1 & 1 & 1 & 1 & 2 & 41 & 67 & 67.5 \\
3 & 1 & 1 & 1 & 1.5 & 2 & 44 & 74 & 80.5 \\
3 & 1 & 1 & 1 & 2 & 2 & 47 & 82 & 94 \\
3 & 1 & 1 & 1 & 2.5 & 2 & 49 & 92 & 109.5 \\
3 & 1 & 1 & 1 & 3 & 2 & 52 & 101 & 123.5 \\
\hline
\end{tabular}


For the design parameters investigated in this study, the diffusion of $\mathrm{CO}_{2}$ in the solid hard coating around particles seems to be the controlling step. The optimum condition of the experimental reactor was found to be $1.059 \mathrm{~m}^{2}$ for the bed surface area, $0.9 \mathrm{~m} / \mathrm{s}$ for the inlet gas velocity, $0.32 \mathrm{~g} / \mathrm{mL}$ for the calcium hydroxide slurry concentration, $1 \mathrm{vol} \%$ for the $\mathrm{CO}_{2}$ concentration, $200{ }^{\circ} \mathrm{C}$ for the inlet gas temperature and $15 \mathrm{~mL} / \mathrm{min}$ for the inlet slurry flow rate. Under the optimum conditions, the $\mathrm{CO}_{2}$ removal efficiency reached a maximum value of $79 \%$.

\section{Acknowledgment}

This work was supported by the office of vice chancellor for research and technology of University of Isfahan under grant number 933411137003.

\section{Nomenclatures}

ANOVA : Analysis of variance, dimensionless

$C_{A g}: \mathrm{CO}_{2}$ concentration in the gas phase, mol.m ${ }^{-3}$

$C_{A r} \quad: \mathrm{CO}_{2}$ concentration on the unreacted core, $\mathrm{mol} . \mathrm{m}^{-3}$

$C_{A s} \quad: \mathrm{CO}_{2}$ concentration on the surface of the layer, mol.m ${ }^{-3}$

$C_{\text {out }} \quad$ : Outlet $\mathrm{CO}_{2}$ concentration, vol\%

$D_{e} \quad: \mathrm{CO}_{2}$ diffusion coefficient through the ash layer

F ratio : Value of the $\mathrm{F}$ distribution, dimensionless

$\mathrm{T}$ Heater : Inlet gas temperature, ${ }^{\circ} \mathrm{C}$

Height : Bed height, mm

$k_{g} \quad:$ Mass transfer coefficient of the gas, $\mathrm{m} . \mathrm{s}^{-1}$

$K^{\prime} \quad$ : Rate constant of the surface reaction, $\mathrm{m}^{4} \cdot \mathrm{mol}^{-1} \cdot \mathrm{s}^{-1}$

$N \quad$ : Number of levels of each factor, dimensionless

P-Value : Probability of finding the observed value, dimensionless

$R \quad$ : Droplet radius, $\mathrm{m}$

$R_{p} \quad$ : Particle radius, $\mathrm{m}$

S/N : Signal-to-noise ratio, dimensionless

$y \quad$ : Experimentally measured removal efficiency, dimensionless

$\left[\mathrm{Ca}(\mathrm{OH})_{2}\right]$ : Calcium hydroxide slurry concentration, g.mL $\mathrm{m}^{-1} \cdot \mathrm{h}^{-1}$

$\% \mathrm{CO}_{2} \quad$ : Carbon dioxide concentration, vol\%

\section{References}

[1] Gupta, H., Fan, L.S. (2002). Carbonationcalcination cycle using high reactivity calcium oxide for carbon dioxide separation from flue gas. Industrial \& Engineering Chemistry Research, 41, 4035-4042. DOI: 10.1021/ie010867l.

[2] Al-Marzouqi, M.H., El-Naas, M.H., Marzouk, S.A.M., Al-Zarooni, M.A., Abdullatif, N., Faiz, R. (2008). Modeling of CO2 absorption in membrane contactors. Separation Purification Technology, 59, 286-293. DOI: 10.1016/j.seppur.2007.06.020.

[3] Global E.V. (2017). outlook 2017, Int. Energy Agency. 1-71. https://www.cleanenergyministerial.org/sites/default/files/201807/GlobalEVOutlook2017.pdf

[4] I.E.A. (International E. Agency), (2008). World energy outlook,. https://www.iea.org/ reports/world-energy-outlook-2008

[5] Beisheim, T., Zieba, M., Scheffknecht, G. (2013). Experimental investigations on deposit formation by recarbonation on external heat exchanger surfaces in oxyfuel CFB boilers, in: Energy Procedia,: pp. 1283-1290. DOI: $10.1016 /$ j.egypro.2013.06.003.

[6] Van der Hoeven, M. (2012). $\mathrm{CO}_{2}$ Emissions from Fuel Combustion: Highlights, Int. Energy Agency, Fr..

[7] Haghnegahdar, M.R., Hatamipour, M.S., Rahimi, A. (2010). Removal of carbon dioxide in an experimental powder-particle spouted bed reactor. Separation Purification Technolo g y, $\quad 72, \quad 288-293$. D O I : 10.1016/j.seppur.2010.02.019.

[8] Dieter, H., Hawthorne, C., Zieba, M., Scheffknecht, G. (2013). Progress in calcium looping post combustion $\mathrm{CO}_{2}$ capture: successful pilot scale demonstration. Energy Procedia. 37, 48-56.

[9] Charitos, A., Hawthorne, C., Bidwe, A.R., Sivalingam, S., Schuster, A., Spliethoff, H., Scheffknecht, G. (2010). Parametric investigation of the calcium looping process for $\mathrm{CO}_{2}$ capture in a $10 \mathrm{kWth}$ dual fluidized bed. Int. J. Greenh. Gas Control., 4, 776-784.

[10] Dieter, H., Bidwe, A.R., Varela-Duelli, G., Charitos, A., Hawthorne, C., Scheffknecht, G. (2014). Development of the calcium looping $\mathrm{CO}_{2}$ capture technology from lab to pilot scale at IFK, University of Stuttgart. Fuel, 127, 23-37.

[11] Kremer, J., Galloy, A., Stroehle, J., Epple, B. (2013). Continuous $\mathrm{CO}_{2}$ capture in a $1-\mathrm{MWh}$ carbonate looping pilot plant. Chemical Engineering Technology, 36, 1518-1524. 
[12] Ströhle, J., Junk, M., Kremer, J., Galloy, A., Epple, B. (2014). Carbonate looping experiments in a 1 MWth pilot plant and model validation. Fuel, 127, 13-22.

[13] Varel, G.D., Bernard, L., Bidwe, A.R., StackLara, V., Hawthorne, C., Zieba, M., Scheffknecht, G. (2013). Calcium looping process: experimental investigation of limestone performance regenerated under high $\mathrm{CO}_{2}$ partial pressure and validation of a carbonator model. Energy Procedia, 37, 190-198.

[14] Sánchez-Biezma, A., Paniagua, J., Diaz, L., Lorenzo, M., Alvarez, J., Martínez, D., Arias, B., Diego, M.E., Abanades, J.C. (2013). Testing postcombustion $\mathrm{CO}_{2}$ capture with $\mathrm{CaO}$ in a 1.7 MWt pilot facility. Energy Procedia, 37, $1-8$.

[15] Symonds, R.T., Champagne, S., Ridha, F.N., $\mathrm{Lu}$, D.Y. (2016). $\mathrm{CO}_{2}$ capture performance of $\mathrm{CaO}-$ based pellets in a $0.1 \mathrm{MWh}$ pilot-scale calcium looping system. Powder Technology, $290,124-131$.

[16] Charitos, A., Rodríguez, N., Hawthorne, C., Alonso, M., Zieba, M., Arias, B., Kopanakis, G., Scheffknecht, G., Abanades, J.C. (2011). Experimental validation of the calcium looping $\mathrm{CO}_{2}$ capture process with two circulating fluidized bed carbonator reactors. Industrial Engineering Chemistry Research, 50, 96859695.

[17] Symonds, R.T., Lu, D.Y., Manovic, V., Anthony, E.J. (2012). Pilot-scale study of $\mathrm{CO}_{2}$ capture by $\mathrm{CaO}$-based sorbents in the presence of steam and SO2. Industrial Engineering Chemistry Research, 51, 7177-7184.

[18] Kavoshi, L., Hatamipour, M.S., Rahimi, A. (2013). Kinetic modeling of reactive absorption of carbon dioxide in a spray dryer. Chemical Engineering Technology, 36, 500-506. DOI: $10.1002 /$ ceat.201200304.

[19] Shimizu, T., Hirama, T., Hosoda, H., Kitano, K., Inagaki, M., Tejima, K. (1999). A twin fluid-bed reactor for removal of $\mathrm{CO}_{2}$ from combustion processes. Chemical Engineering Research \& Design, 77, 62-68. DOI: $10.1205 / 026387699525882$.

[20] Abanades, J.C., Anthony, E.J., Lu, D.Y., Salvador, C., Alvarez, D. (2004). Capture of $\mathrm{CO}_{2}$ from combustion gases in a fluidized bed of CaO. AIChE J., 50, 1614-1622. DOI: 10.1002/aic.10132.
[21] Hanak, D.P., Anthony, E.J., Manovic, V. (2015). A review of developments in pilotplant testing and modelling of calcium looping process for $\mathrm{CO}_{2}$ capture from power generation systems. Energy Environ. Sci., 8, 2199-2249. DOI: 10.1039/c5ee01228g.

[22] Han, S.J., Yoo, M., Kim, D.W., Wee, J.H. (2011). Carbon dioxide capture using calcium hydroxide aqueous solution as the absorbent. Energy and Fuels, 25, 3825-3834. DOI: 10.1021/ef200415p.

[23] Chen, B., Laucks, M.L., Davis, E.J. (2004). Carbon dioxide uptake by hydrated lime aerosol particles. Aerosol Science Technology, 38, 588-597.

[24] Lin, C.C., Chen, B.C., Chen, Y.S., Hsu, S.K. (2008). Feasibility of a cross-flow rotating packed bed in removing carbon dioxide from gaseous streams. Sepparation Purification Technology, 62, 507-512. DOI: 10.1016/j.seppur.2008.02.019.

[25] Beruto, D.T., Botter, R. (2000). Liquid-like $\mathrm{H}_{2} \mathrm{O}$ adsorption layers to catalyze the $\mathrm{Ca}(\mathrm{OH})$ ${ }_{2} / \mathrm{CO}_{2}$ solid-gas reaction and to form a nonprotective solid product layer at $20^{\circ}$ C. J. Eur. Ceram. Soc., 20, 497-503.

[26] Roy, R. (2001). Design of Experiment Using The Taguchi Approach: 16 step to product and process improvement. Technometrics, 44, 289-289. DOI: 10.1198/004017002320256440.

[27] Istadi, I., Suherman, S., Buchori, L. (2010). Optimization of reactor temperature and catalyst weight for plastic cracking to fuels using response surface methodology. Bulletin of Chemical Reaction Engineering \& Catalysis, 5 (2), 103-111. DOI: 10.9767/bcrec.5.2.797. 103-111

[28] Cook, P.J. (2006). Carbon dioxide capture and geological storage: Research, development and application in Australia. Int. J. Environ. Stud . , $63, \quad 731-749$. D O I : 10.1080/00207230601047073.

[29] Shih, S.M., Ho, C.S., Song, Y.S., Lin, J.-P. (2002). Kinetics of the Reaction of $\mathrm{Ca}(\mathrm{OH})_{2}$ with $\mathrm{CO}_{2}$ at Low Temperature. Industrial Engineering Chemistry Research, 38, 1316-1322. DOI: 10.1021/ie980508z. 